\title{
RESEARCH PAPER \\ EVALUATION OF A MODIFIED PASSIVE SOLAR HOUSING SYSTEM FOR POULTRY BROODING
}

\author{
T. U. Nwakonobi ${ }^{1}$, S. E. Obetta ${ }^{1}$ and M. N. Gabi. ${ }^{2}$ \\ ${ }^{l}$ Department of Agric and Environmental Engineering, University of Agriculture, \\ Markurdi, Benue State, Nigeria. \\ Corresponding author: email: napeth66@yahoo.com \\ ${ }^{2}$ Agricultural Research Council of Nigeria, FCT, Abuja, Nigeria
}

\begin{abstract}
A modified passive solar poultry brooding system was tested for its performance at full capacity for a brooding period of four (4) weeks for broiler chicks. Its performance was evaluated through the determination of thermal environmental properties as well as physiological development of brooded chicks for a period of 4 weeks. The temperature levels obtained in the brooding space were in the range of $28^{\circ} \mathrm{C}-35^{\circ} \mathrm{C}$. The maximum average weight per chick attained at the end of brooding period was $566.5 \mathrm{~g}$. Only $6.7 \%$ loss was incurred and feed conversion ratio decreased from 1.5 in the first week to 1.1 by the end of the brooding period indicating better performance. The hourly efficiency of the solar brick passive system was estimated at about 78.42\% in a day of May and $92.73 \%$ in a day of June. The modified solar housing system met the temperature requirements $\left(27^{\circ} \mathrm{C}-35^{\circ} \mathrm{C}\right)$ for the broiler chicks within the $4-5$ weeks of brooding period.
\end{abstract}

Keywords: clay bricks, passive solar system, chick brooding, performance evaluation, Nigeria

\section{INTRODUCTION}

A brooding house is a facility that can accomplish the process of brooding usually carried out by hen in order to raise their young ones from the day of hatching to a period of about four weeks. According to (Hermes, 1999), during this period of bird's life, the most important needs are warmth, protection, feed and water. This brooding process involves keeping the young chicks at the natural brooding temperature of which they are naturally kept under a caring mother. A brooder house development involves meeting this critical temperature requirement and controlling same as the chicks grow or when the need arises. For chick brooding, maximum temperature of $35^{\circ} \mathrm{C}$ is required (Okonkwo, 2001). Brooding stage is the most critical period in the life of the birds and there can be more deaths during this short period than through the rest of the birds lives (Kekeocha, 1982).

The quality of heat supply during brooding stage determines the physical and physiological 


\section{$51 \quad$ Nwakonobi et al.}

development and the mortality rate of the chicks. Most poultry farmers use combination of kerosene lamps and stoves for heating and brooding chicks particularly in developing countries. Electric energy using electric bulbs were also adopted for poultry production. Due to high cost and unavailability of kerosene in most developing countries including Nigeria, many farmers cannot afford either to start raising poultry or to expand their existing poultry production. In addition, those few farmers who use electricity as heat source often suffer power outage resulting in the loss of young chicks (Okonkwo, 1998). The mortality rates of $7 \%$ and $10 \%$ have been reported of chicks brooded in kerosene and grid based system respectively, (Okonkwo and Akubuo, 2007). The high mortality rate may be due to the $\mathrm{CO}_{2}$ and $\mathrm{CO}$ emissions or outbreak of fire. The traditional method of leaving chicks to be brooded by their mothers for their first few days of life results in mortality rate of $60-70 \%$ (Okonkwo, 1998).

Due to constraints encountered in the use of conventional systems in poultry production, solar energy is an attractive energy option which is always available for utilization and environmental friendly.

This study evaluates the physical and biological performances of the modified passive solar brooder built of locally produced clay bricks. The hourly heat efficiency of the brooding house was estimated for a typical day in the month of May and June, the rainy season and most critical season of the year.

\section{MATERIALS AND METHOD \\ The Materials}

The abundant locally burnt clay bricks were used to build the brooder walls to serve as collector and storage media of the heat energy from the sun. The fibre glass serves as a cover material to the collector.

The description of the passive solar poultry chick brooder.

The poultry brooding house by Ahiaba (2009) consists of rectangular shape clay brick masonry wall with internal dimension measuring $1.4 m \times 1.0 m \times 1.8 m$ in size, laid with cement mortar (see Fig. 1). This gives a floor area of $1.4 \mathrm{~m}^{2}$ to house 30 broiler chicks under brooding with a stocking density of $0.04 \mathrm{~m}^{2}$ per chick giving $20 \%$ extra space for drinkers and feed troughs as well as adequate space to accommodate the attendant of the brooding birds. Ventilation openings were fixed at the east and west ends of the brooding house. A vent size of $0.3 \mathrm{~m}$ $\mathrm{x} 0.15 \mathrm{~m}$ fixed at the eastern end has a wooden shutter. The door located at the western side was not completely sealed to induce fresh air from the west to flow into the brooding room naturally causing cross ventilation and removing the used air in the room. All the openings were provided with $0.5 \mathrm{~mm}$ diameter nets to prevent or keep of rodents and insects.

The clay brick wall, $0.22 m$ thick, duly oriented southward for maximum solar energy collection all the year round, form the thermal storage media for the brooder. The external surface of the wall was treated with black paint to serve as absorber of radiant energy from the sun as black surfaces absorb heat rather than reflecting it. The absorber wall has four vents measuring $0.05 m \times 0.1 m$ each; two vents are located at the upper and lower part of the wall, respectively. The collector was covered with a single fiber glass, distanced at air gap of $0.1 \mathrm{~m}$. A heat exchanger to provide supplementary heat during sunless hours was installed next to the brooding chamber. It is made of lagged or insulated wooden box containing rock pebbles as heat storage medium, also covered with glazing material. It is connected to the brooding chamber by air ducts which serve as hot air flow channels to transmit heat to the brooding chamber.

\section{The Modifications on the Passive Solar Brooder}

Fig. 2 shows the modified passive solar brooder. The heat exchanger which forms the integral part of the brooder by Ahiaba (2009) was disconnected and the brick wall tested for its heat collection and transmission efficiency 
Evaluation of poultry brooding system ... 52

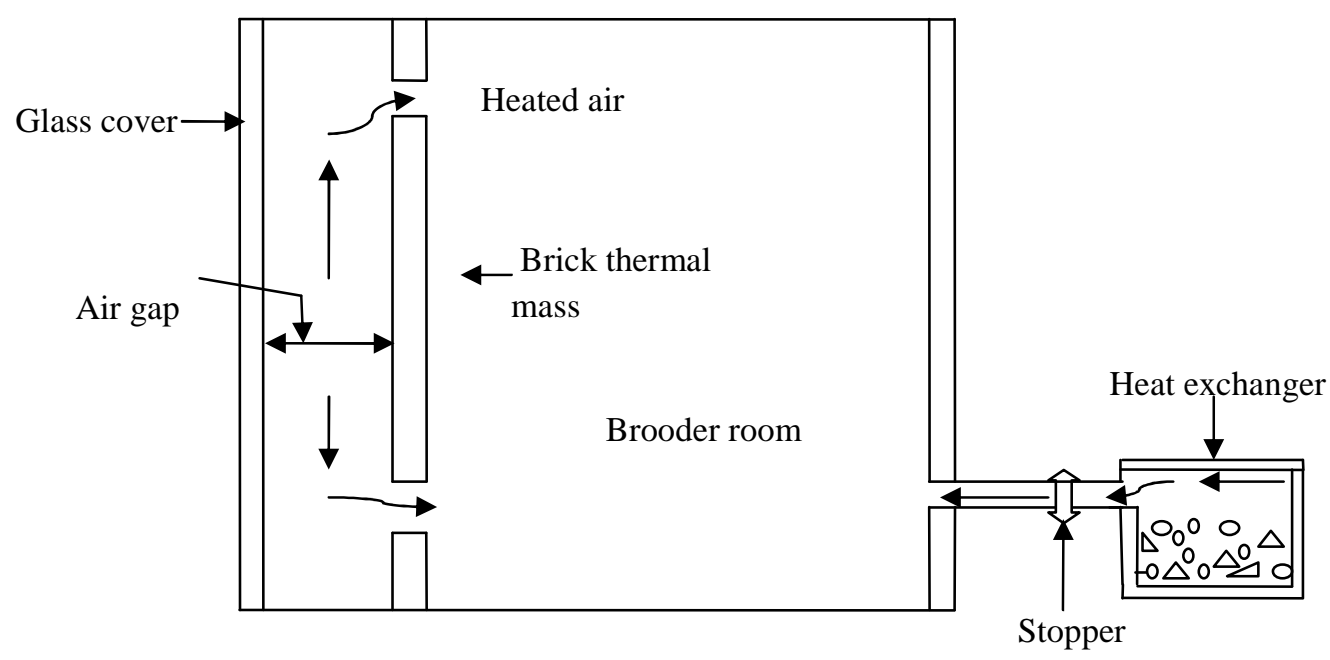

Fig. 1: The passive solar poultry brooder

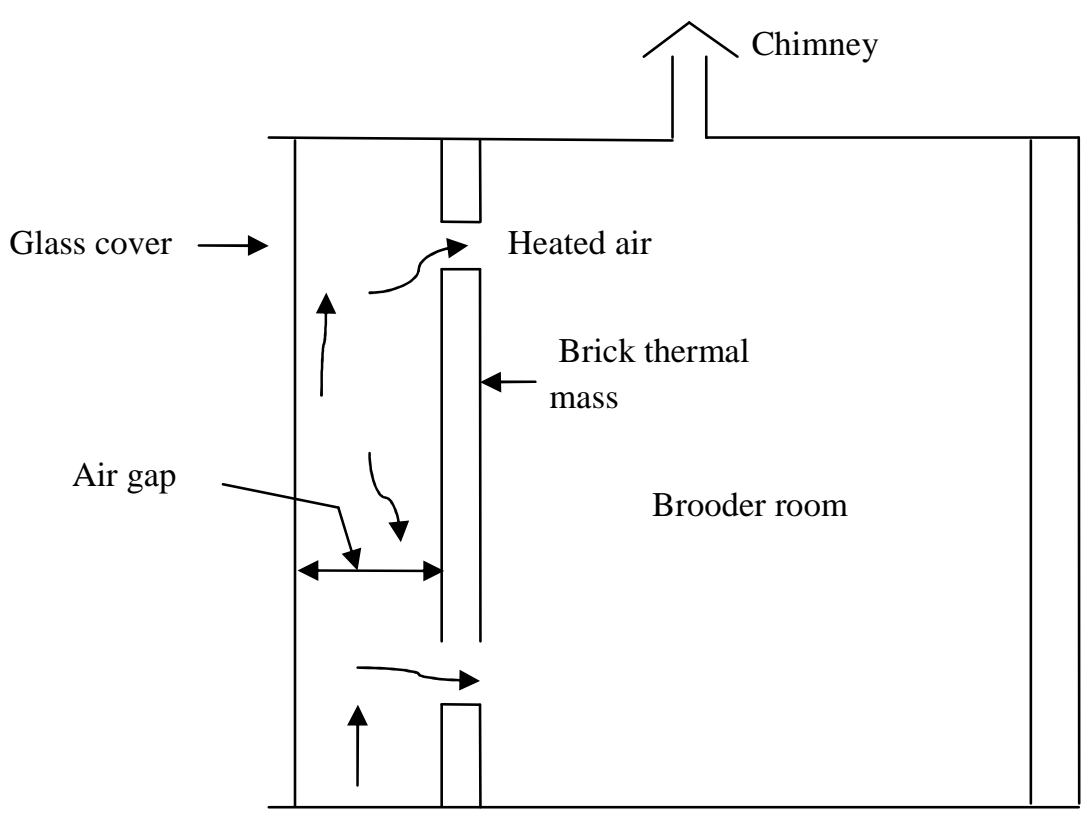

Fig. 2: The modified passive solar poultry brooder 


\section{$53 \quad$ Nwakonobi et al.}

into the brooding room at different hours of the day. The brick masonry which absorbs heat slowly also emits heat slowly and is therefore good heat storage medium to keep brooding room warm during sunless hours. The brooding room was provided with insulating ceiling to reduce excess heat loss during sunless hours particularly at night and early hours of the morning. A chimney was incorporated for the escape of hot fluid and to regulate the temperature of the brooding space. It helps in reducing the unwanted odours generated by the emitted gases such as ammonia and eliminates its health hazard to the chicks. The chimney fitted with insect screen and cap is mounted at the roof top. The brooding room deep litter floor was provided with cement screen (smooth finish) to prevent damp on the litter.

\section{The Performance Evaluation}

The physical and biological performance evaluations were conducted of the modified solar passive system. The physical performance evaluation involved monitoring of the temperature level attained by the solar collector. Temperature sensors were used to monitor the temperature of the brooding chamber, the brick masonry wall and air gap. The temperature readings were taken at morning (6:00am), noon and evening (4:00pm) for a period of one week before the birds were stocked in the brooder. The temperature monitoring of the solar brooding system was continued throughout the brooding period of 28 days.

The biological performance evaluation involved monitoring of weight gain, cumulative feed consumption and feed conversion ratio of the brooded chicks for four weeks. The brooding room was stocked with 30 broiler chicks which were one-day old obtained from a reliable commercial hatchery. In order to maintain proper growth rate of the broiler chicks in the brooding house; the chicks were fed ad libatum or continuously throughout the brooding period. Good quality water was administered to the chicks while disease preventive measures were provided in accordance with the prescri- ption of a veterinary expert. The weights of the chicks were taken at one day-old and each week for a period of four weeks. The average weight of the chicks and their cumulative feed consumptions were measured. The feather development of the chicks was also taken into consideration.

\section{RESULTS AND DISCUSSION}

Results of Physical Performance Evaluation

The minimum and maximum daily temperatures recorded at the various parts of the brooding house for seven days in the month of May are presented in Table 1 . The results in Table 1 show that the brooder room temperature was maintained at the average range of $28^{\circ} \mathrm{C}-35^{\circ} \mathrm{C}$ which is very close to the value of $30^{\circ} \mathrm{C}-$ $35.3^{\circ} \mathrm{C}$ obtained by Ahiaba (2009), the mean inner surface brick wall temperature ranges between $28^{\circ} \mathrm{C}-39^{\circ} \mathrm{C}$ which is almost similar to $29^{\circ} \mathrm{C}-39^{\circ} \mathrm{C}$ by Ahiaba (2009). The ambient temperature ranges between $23^{\circ} \mathrm{C}-30^{\circ} \mathrm{C}$. The maximum temperatures were obtained between 12 noon and 4:00pm while the minimum was obtained in the early hours of 6:00am. Since the month of May is the onset of rainy season, which is cloudy most of the hours of the day, it indicates that passive solar brick system performs well even at critical period such as cloudy days.

\section{Results of the Biological Performance Evaluation}

The biological performance evaluation was carried out between the month of May and June when the rains have already set in which resulted in intermittent rainfall, cloud cover and sunshine. From the results of the weight measurement of the chicks taken at weekly interval for four weeks (see Table 2), the average weight gain per chick from week 1 to week 4 ranged between $34.2 \mathrm{~g}$ and $566.5 \mathrm{~g}$, respectively. Plates $1-4$ show chicks at various weeks of brooding. The average weight, $566.5 \mathrm{~g}$ attained at the end of the brooding period shows a close performance when compared with 585 grams reported by Okonkwo and Akubuo (2007) in 28 days brooding of broiler chicks in sandcrete 
Table 1: Mean temperatures of the various parts of the brooding house

\begin{tabular}{cccccccc}
\hline DAY & $\begin{array}{l}\text { Ambient } \\
\text { temperature }\left({ }^{\mathbf{}} \mathbf{C}\right)\end{array}$ & \multicolumn{3}{l}{$\begin{array}{l}\text { Brooder } \\
\text { temperature }\left({ }^{\circ} \mathbf{C}\right)\end{array}$} & \multicolumn{2}{l}{$\begin{array}{l}\text { Inner wall surface } \\
\text { Temperature }\left({ }^{\circ} \mathbf{C}\right)\end{array}$} & $\begin{array}{l}\text { Brick wall } \\
\text { Temperature } \\
\left({ }^{\circ} \mathbf{C}\right)\end{array}$ \\
& Max. & Min. & Max. & Min. & Max. & Min. & \\
\hline 1 & 30.7 & 28.5 & 36.2 & 28.7 & 38.2 & 30.3 & 38.3 \\
2 & 27.7 & 26 & 33.7 & 27.2 & 36.3 & 28.7 & 36.7 \\
3 & 30.7 & 29 & 35.7 & 29.3 & 38.3 & 31 & 39 \\
4 & 24.8 & 23.7 & 32.8 & 24.5 & 35.5 & 28.5 & 36 \\
5 & 29.5 & 28.8 & 35.5 & 28.9 & 38 & 30.3 & 38.3 \\
6 & 29.5 & 27.7 & 36.2 & 29.5 & 38.7 & 31.3 & 39.3 \\
7 & 30.2 & 27.8 & 36.3 & 29.8 & 39 & 31.7 & 39.7 \\
\hline
\end{tabular}

masonry wall.

The cumulative feed consumption per chick was monitored for a period of four weeks and the results presented in Table 3. The results show the cumulative feed consumption per chick to be $1,369.7 \mathrm{~g}$ which is slightly higher than $1,253 \mathrm{~g}$ obtained by Okonkwo and Akubuo (2007). The increase in feed intake may be as a result of healthy room environment. At the end of the brooding period, out of the 30 chicks that entered the brooding house, 28 chicks came out alive. This shows $6.7 \%$ mortality rate indicating $93.3 \%$ survival for the brooded chicks. Okonkwo and Ukachukwu (2004) reported $3 \%, 9 \%$ and $10 \%$ mortality rate for solar, kerosene and electricity brooding respectively.

The feed conversion rate expressed as the ratio of the amount of feed consumed to total weight gained was also obtained (Table 3). The relationship of conversion rate against weeks show highest value at first week and decrease till third week when it shows slight increase towards the end of brooding period. This may be due to the little stress on chicks when Gomboro vaccine was administered to them which are usually within this period.
Efficiency of the Passive Solar Brick System The hourly efficiency of the solar system was calculated from the equation given by Bansal and Gour (1997) which is given as:

$$
\begin{gathered}
\eta_{H}=\frac{\mathrm{Q}_{\mathrm{ud}}}{\mathrm{Q}_{\mathrm{gc}}} \\
Q_{u d}=\mathrm{Q}_{\mathrm{ag}}+Q_{t w} \\
Q_{t w}=h_{b r} A_{t w}\left(T_{b s}-T_{r m}\right) \\
Q_{a g}=2 \dot{\mathrm{mC}}_{\mathrm{pa}}\left(T_{a g}-T_{r m}\right)
\end{gathered}
$$

The expression for the mass air flow rate is given by Bansal and Gour (1997) and Zriken and Bilgen (1987) as:

$\dot{\mathrm{m}}=\rho_{\mathrm{a}} A_{v} F_{r} \sqrt{\frac{g D_{v}\left(T_{a g}-T_{r m}\right)}{T_{a g}+T_{r m}}}$

The solar energy incident on the glass cover during an hour is given by;

$\mathrm{Q}_{\mathrm{gc}}=\mathrm{A}_{\mathrm{gc}} \mathrm{I}_{\mathrm{gc}}$ 


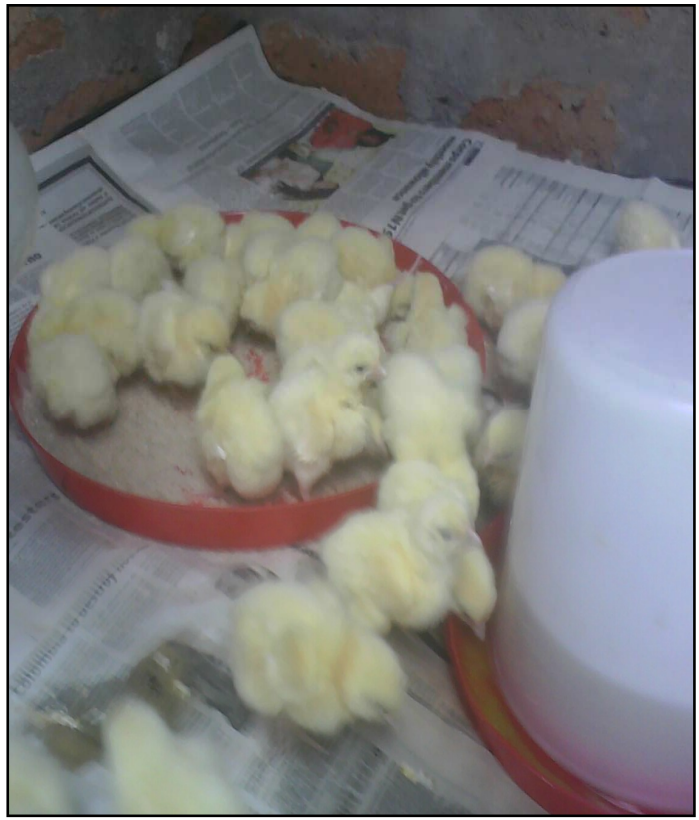

Plate 1: 1-week old chicks in a brooder

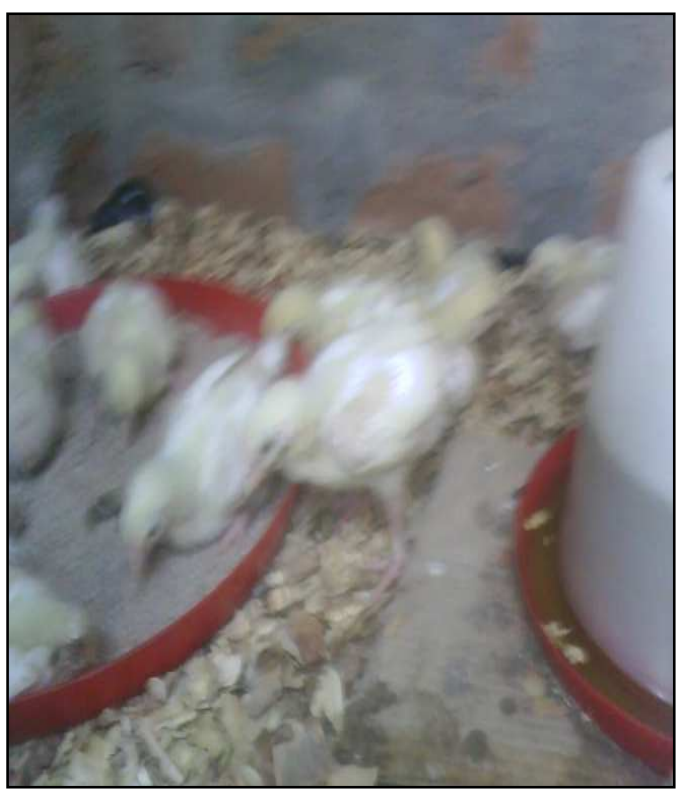

Plate 2: 2-week old chicks in a brooder

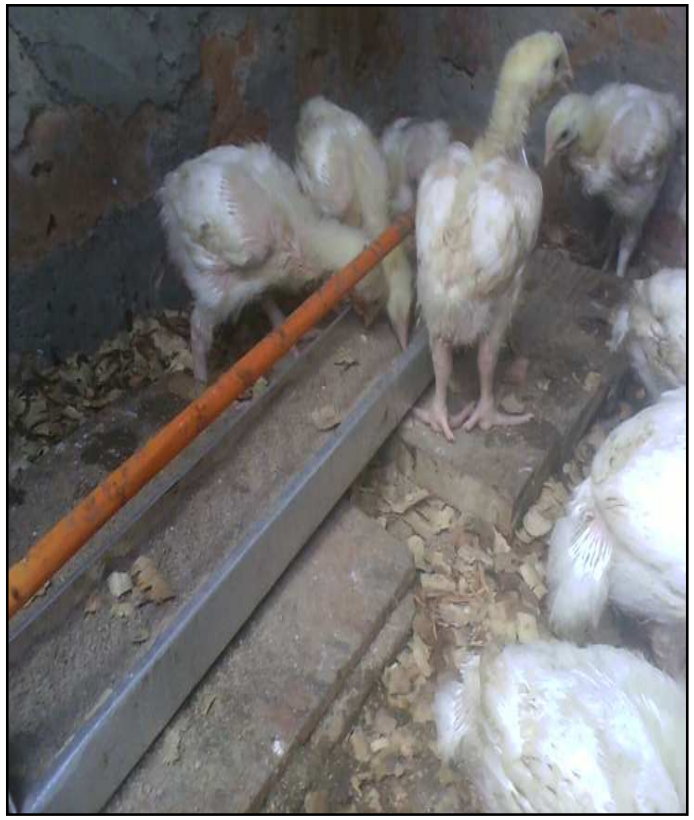

Plate 3: 3-week old chicks in a brooder

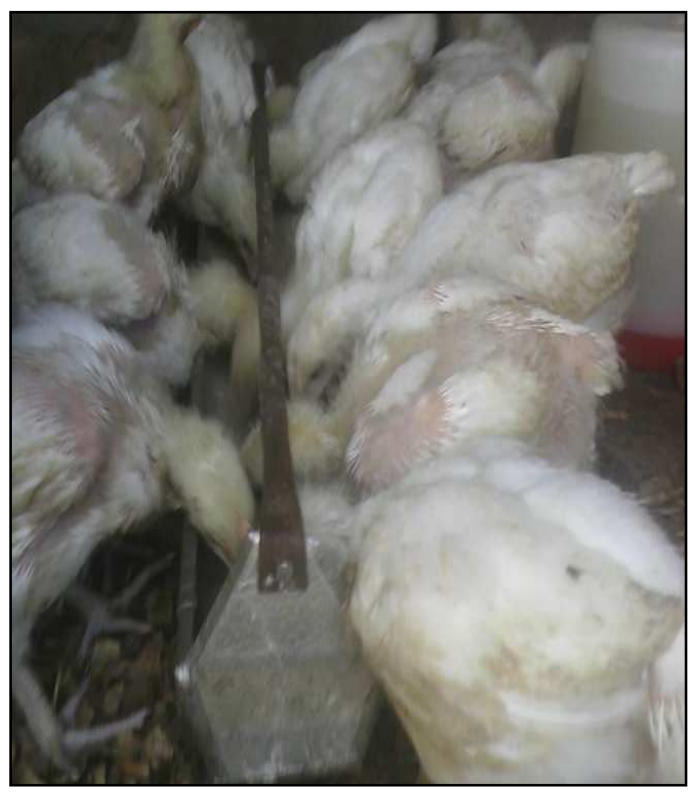

Plate 4: 4-week old chicks in a brooder 
Table 2: Results of weight gain at various brooding period

\begin{tabular}{lccccc}
\hline Age of birds (days) & 1 & 7 & 14 & 21 & 28 \\
\hline Average Weight attained (g) & 34.2 & 92.1 & 192.2 & 392.6 & 566.5 \\
\hline
\end{tabular}

Table 3: Cumulative feed intake and conversion ratio at different brooding period

\begin{tabular}{cccc}
\hline Week & Cumulative feed consumed $(g)$ & Weight of birds $(g)$ & Conversion ratio \\
\hline 1 & 4,175 & 2,764 & 1.5 \\
2 & 7,155 & 5,766 & 1.2 \\
3 & 12,221 & 11,779 & 1.0 \\
4 & 17,541 & 15,863 & 1.1 \\
\hline
\end{tabular}

Table 4: The hourly efficiency for the selected day in the middle of months of May and June

\begin{tabular}{|c|c|c|}
\hline & May & June \\
\hline Time & Hourly Efficiency (\%) & Hourly Efficiency (\%) \\
\hline 06.00 & 37.40 & 41.14 \\
\hline 07.00 & 37.40 & 41.14 \\
\hline 08.00 & 50.15 & 53.68 \\
\hline 09.00 & 52.56 & 56.24 \\
\hline 10.00 & 43.28 & 53.68 \\
\hline 11.00 & 37.40 & 52.77 \\
\hline 12.00 & 37.40 & 68.79 \\
\hline 13.00 & 51.25 & 71.36 \\
\hline 14.00 & 66.67 & 87.58 \\
\hline 18.00 & 78.42 & 92.73 \\
\hline
\end{tabular}

The efficiency of the solar brick wall at the various times of the day selected in the middle of the month of May and June is presented in Table 4. It was clearly observed that the hourly efficiency was slightly low in the morning time up to noon time but increases during the evening hours. This trend could be attributed to large quantity of stored heat being conducted and radiated from the passive wall into the brooding space during the evening period. 


\section{$57 \quad$ Nwakonobi et al.}

Higher hourly efficiency of $41.14 \%$ and $92.73 \%$ in the morning and evening respectively were attained in the month of June while hourly efficiency of $37.4 \%$ and $78.42 \%$ were attained in the morning and evening time of the day of May. The higher efficiency values in June than May could be attributed to more frequent rain that occurred in May than June period.

\section{CONCLUSION}

The results of this study indicate that locally burnt clay bricks could be used to build passive solar walls for chick brooding since it can maintain temperature range of $28-35^{\circ} \mathrm{C}$ in the May - June, the month of rainy season. The efficiency of brick walls in transmitting heat energy to the brooding room is lowest in the morning, $37.40 \%$ and $41.14 \%$ for the month of May and June, respectively; and highest in the evening, $78.42 \%$ and $92.73 \%$ for the month of May and June, respectively. It is therefore a good thermal mass. Brooding system experiment conducted simultaneously in both Ahiaba (2009) passive solar design and the modified brooder house is recommended in further studies for effective experimental control.

\section{REFERENCES}

Ahiaba, V. U. (2009). "Design, construction and Testing of Solar Brooding House in Makurdi Metropolis.” B.Eng. Project submitted to the Department of Agricultural and Environmental Engineering, University of Agriculture, Makurdi, Nigeria.

Bansal, N. K. and Gour, B. C. (1997). Application of $\mathrm{U}$ and $\mathrm{G}$ values for Sizing Passive Heating Concepts." Solar energy 57(5): 361 -372 .

Hermes, J. C. (1999), Extension Poultry Specialist, Oregun State University. Replaces Oregun State University Extension Publication E.C. 854.

Kekeocha, C. C. (1982). Pfizer Poultry Production Handbook, $2^{\text {nd }}$ Edition London,
McMillan Publisher.

Okonkwo, W. I. (1998). Solar Energy Brooding System, in Rural Renewable Energy Needs and Five Supply Technologies. Publication of Energy Commission of Nigeria.

Okonkwo, W. I. (2001). Thermal Analysis and Evaluation of a Passive Solar energy Poultry chick Brooder. NIAE Proceedings of the International conference held at Enugu, Nigeria, Vol. 23: 374 - 385 .

Okonkwo, W. I. and Ukachukwu, S. N. (2004). Effects of Passive Solar, Electric and Kerosene Brooding Systems on the performance of Broiler Chickens, Journal of Sustainable Agriculture and the Environment 6 (1): 1- 6.

Okonkwo, W. I. and Akubuo, C. O. (2007). Masonry Wall System for Poultry Brooding. International Journal of Poultry Science 6 (2): $125-130$. Asian Network for Scientific Information.

Zrikem, Z. and Bilgen, F. (1987). "Theoretical study of a composite Trombe - Michael Wall Solar Collector System," Solar Energy. 39 (5): $409-419$.

\section{NOMENCLATURE}

$Q_{u d}=$ total useful energy delivered into the room during the hour

$Q_{g c}=$ solar energy incident on the glass cover during the same period

$Q_{a g}=$ heat transferred into the room by the heated air in the air gap

$Q_{t w}=$ heat transferred by conduction through the brick wall and radiation from the wall's back surface to the room

$\mathrm{h}_{\mathrm{br}}=$ radiation heat transfer coefficient from the back surface of the wall to the brooder

$\dot{\mathrm{m}}=$ mass flow rate

$\mathrm{C}_{\mathrm{pa}}=$ specific heat capacity of air

$\rho_{a}=$ density of air room 
Evaluation of poultry brooding system ... 58

$\mathrm{A}_{\mathrm{v}}=$ upper vent area

$\mathrm{F}_{\mathrm{r}}=$ froude number

$\mathrm{D}_{\mathrm{v}}=$ vertical distance as between the upper and the lower vents
$\mathrm{A}_{\mathrm{gc}}=$ glass cover surface area

$I_{g c}=$ the hourly total solar radiation on the glass cover

$\eta_{H}=$ hourly efficiency 